Germanistische Abhandlungen

VON DER "ZAUBERFLÖTE« ZUM »LOHENGRIN" 


\title{
Von der »Zauberflöte« zum »Lohengrin«
}

\author{
Das deutsche Opernlibretto in der ersten Hälfte \\ des 19. Jahrhunderts
}

J.B. METZLERSCHE VERLAGSBUCHHANDLUNG STUTTGART 


\section{GERMANISTISCHE ABHANDLUNGEN 64}

Die vorliegende Studie ist die leicht überarbeitete Fassung der im Herbst 1988 von der

Philosophischen Fakultät der Westfälischen Wilhelms-Universität zu Münster angenommenen Dissertation mit dem Titel »Von der `Zauberflöte` zum `Lohengrin«.

Deutsche Operntexte zwischen ıIdealismus` und `Realismus«"

CIP-Titelaufnahme der Deutschen Bibliothek

Nieder, Christoph:

Von der "Zauberflöte" zum "Lohengrin" : das deutsche

Opernlibretto in der ersten Hälfte des 19. Jahrhunderts /

Christoph Nieder. - Stuttgart : Metzler, 1989

(Germanistische Abhandlungen ; 64)

ISBN 978-3-476-00675-2

ISBN 978-3-476-03292-8 (eBook)

DOI 10.1007/978-3-476-03292-8

NE: GT

Dieses Werk einschließlich aller seiner Teile ist urheberrechtlich geschützt. Jede Verwertung auBerhalb der engen Grenzen des Urheberrechtsgesetzes ist ohne Zustimmung des Verlages unzulässig und strafbar. Das gilt insbesondere für Vervielfältigungen, Übersetzungen, Mikroverfilmungen und die Einspeicherung und Verarbeitung in elektronischen Systemen.

(C) 1989 Springer-Verlag GmbH Deutschland Ursprünglich erschienen bei J.B. Metzlersche Verlagsbuchhandlung und Carl Ernst Poeschel Verlag GmbH in Stuttgart 1989 


\section{VORBEMERKUNG}

Auch mein Interesse an der Oper wurde natürlich nicht durch den Text, sondern durch die Musik geweckt; literaturwissenschaftlich vorbelastet, schien es mir jedoch, daß die Texte bei aller sprachlichen Unzulänglichkeit viel Interessantes enthalten, worüber der durchschnittliche Opernfreund hinweghört, das aber in einem engen Zusammenhang mit Literatur und Geschichte der jeweiligen Zeit steht. Mein Ziel ist es, darauf hinzuweisen, daß es in den Operntexten einiges zu entdecken gibt und eine vorläufige Einordnung der Texte in einen geistesgeschichtlichen Zusammenhang vorzunehmen.

Besonders hinweisen möchte ich noch auf die Anmerkungen, die aus technischen Gründen ans Ende des Buches verbannt werden mußten: Sie enthalten nicht nur Nachweise, sondern zeigen zusätzliche Querverbindungen auf und bieten illustrierende und vertiefende Einzelheiten.

Ich danke den Bibliothekarinnen und Bibliothekaren der Universitätsbibliotheken Münster und Konstanz, der Bayrischen Staatsbibliothek, der Bibliothek des Theatermuseums und der Stadtbibliothek in München sowie der Stadtbücherei Herten, die für mich den Fernleihverkehr übernommen haben.

Vor allem aber danke ich meinem Doktorvater Herrn Professor Hubert Ohl, der sich auf dieses für einen Germanisten noch immer ungewohnte Thema eingelassen und mir dabei geholfen hat, meine Opernbegeisterung in einigermaßen geordnete Bahnen zu lenken. 
MEINEN ELTERN 


\section{Voraussetzungen}

1.1 Oper und Literaturwissenschaft . . . . . . . . . . . . . . . . . . . . . 2

$1.2 \mathrm{Zu}$ dieser Arbeit . . . . . . . . . . . . . . . . . . 6

\section{Oper als dramatische Kunstform}

2.1 Zur Dramaturgie der Oper . . . . . . . . . . . . . . . . 11

2.2 Die Entwicklung der deutschen Oper bis zum Ende des 18. Jahrhunderts . . . . 15

2.3 Bürgerliche Theaterkultur . . . . . . . . . . . . . . . . . 18

2.4 Italienische, deutsche und französische Oper . . . . . . . . . . . . . . . . 24

3 Der Text in der Oper

3.1 Literatur und Musik . . . . . . . . . . . . . . . . . . . 30

3.2 Die Zusammenarbeit von Dichter und Komponist bei der Entstehung des Librettos . . . . . . . . . . . . . . . . . 33

3.3 Zur Operntextrezeption ............................ 38

3.4 Die Operndichter: Aspekte der sozialen und literarischen Stellung . . . . . . . . 42

4 Oper als Drama I: Idealismus

4.1 Idee und Wirklichkeit . . . . . . . . . . . . . . . . . 50

4.2 Natur und Kultur . . . . . . . . . . . . . . . . . . . . . . . . . . . . . . . . 61

4.3 Der Tod als Prüfung . . . . . . . . . . . . . . . . 66

4.4 Liebe als moralische $\mathrm{Kraft} \ldots \ldots \ldots$. . . . . . . . . . . . 68

4.5 Mensch und Unmensch . . . . . . . . . . . . . . . . . . . . 74

4.6 Herrschaftsformen . . . . . . . . . . . . . . . . . . 80

\section{Oper als Gesellschafts-Spiel: Biedermeierzeit}

5.1 Wirklichkeit und Spiel . . . . . . . . . . . . . . . . . . . 86

5.2 Bürgerliche Lebenswelt . . . . . . . . . . . . . . . . . . . . . . . . . . . . . . . . . . . . . . . . . .

5.21 Soziale Schichten . . . . . . . . . . . . . . . . . . . . . 93

5.22 Arbeit und Freizeit . . . . . . . . . . . . . . . . . . . . . . . . . 99

5.23 Liebe, Ehe, Familie . . . . . . . . . . . . . . . . . . . . . . . . . . . . . . . . . . . . . . . . . . . . . . . . . . .

5.3 Spielmöglichkeiten . . . . . . . . . . . . . . . . . . . . . . 111

5.31 Kulissen und Maskeraden: Das Spiel mit der »Natur» . . . . . . . . . . . . . . 111

5.32 Bildungsgut und Tagesgeschehen . . . . . . . . . . . . . . . . . . . . . . . . . . . . . . . . . 116

5.33 Spiel mit Formen . . . . . . . . . . . . . . . . . . . . . . . . . . . . . 119 
6 Oper als Drama II: Poetischer Realismus

6.1 Traum und Wirklichkeit . . . . . . . . . . . . . . . . . . . . . 127

6.2 Gesellschaft und Individuum . . . . . . . . . . . . . . . . . . . . . 137

6.3 Liebe als Ausbruchsversuch . . . . . . . . . . . . . . . . . . . . . . 140

6.4 Tod und Verklärung . . . . . . . . . . . . . . . . . . . . . . . . . . 144

7 Perspektiven der »Romantischen Oper «

7.1 »Romantische Oper" und biedermeierliche Gesellschaft ． . . . . . . . . . . . . 149

7.2 Literaturoper und Musiktheater . . . . . . . . . . . . . . . . . . . . . 156

8 Anbang

8.1 Opern-Lexikon . . . . . . . . . . . . . . . . . . . 160

8.11 Opernhandlungen . . . . . . . . . . . . . . . . . . . . . . . . . . . . . . . . . . . 160

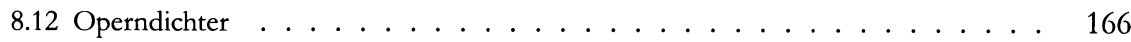

8.2 Zur Textauswahl - Statistisches . . . . . . . . . . . . . . . . 168

8.3 Literaturverzeichnis . . . . . . . . . . . . . . . . . . . 170

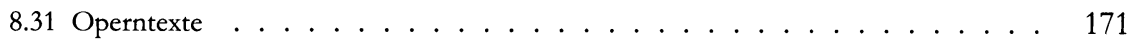

8.32 Kontexte . . . . . . . . . . . . . . . . . . 172

8.33 Sekundärliteratur . . . . . . . . . . . . . . . . . . . 175

9 Anmerkungen . . . . . . . . . . . . . . . . . . . . . 181 